\title{
Psychometric Properties of the Korean Version of the HIV Self-Management Scale in Patients with HIV
}

\author{
Kim, Gwang Suk ${ }^{1}$ Chu, Sang Huil · Park, Yunhee ${ }^{2}$ Choi, Jun Yong ${ }^{3} \cdot$ Lee, Jeong $\mathrm{In}^{4} \cdot$ Park, Chang Gi ${ }^{5} \cdot$ Linda L. McCreary ${ }^{6}$ \\ ${ }^{1}$ Nursing Policy Research Institute, College of Nursing, Yonsei University, Seoul \\ ${ }^{2}$ Department of Nursing, Youngdong University, Youngdong \\ ${ }^{3}$ Department of Internal Medicine, College of Medicine, Yonsei University, Seoul \\ ${ }^{4}$ Division of Nursing, Yonsei University Health System, Seoul, Korea \\ ${ }^{5}$ College of Nursing, University of Illinois at Chicago, Chicago, Illinois \\ ${ }^{6}$ Health Systems Science · College of Nursing, University of Illinois at Chicago, Chicago, Illinois, U. S. A.
}

\begin{abstract}
Purpose: The purpose of this study was to examine validity and reliability of Webel and colleagues' HIV Self-Management Scale when used with a Korean sample. Methods: The original 20-item HIV Self-Management Scale was translated into Korean using translation and back-translation. Nine HIV nurse experts tested content validity. Principal component analysis (PCA) and confirmatory factor analysis (CFA) of data from 203 patients was used to test construct validity. Concurrent validity was evaluated using correlation with patients' self-rating as a "smart patient" measured using a visual analogue scale. Internal consistency was tested by Cronbach's alpha coefficients. Results: All items were rated as having satisfactory content validity. Based on PCA and consideration of conceptual meaning, a three-factor solution was selected, explaining $48.76 \%$ of the variance. CFA demonstrated the adequacy of the three-domain structure of the construct HIV self-management: daily self-management health practices, social support and HIV self-management, and chronic nature of HIV self-management. Goodness-of-fit indices showed an acceptable fit overall with the full model $\left(X^{2} /\right.$ $\mathrm{df}_{(164)}=1.66, \mathrm{RMSEA}=0.06, \mathrm{SRMR}=0.05, \mathrm{TLI}=0.91$, and $\left.\mathrm{CFI}=0.92\right)$. The Korean version of the HIV Self-Management Scale (KHSMS) was significantly correlated with patients' self-rated smart patient $(r=.41)$. The subscale Cronbach's alpha coefficients ranged from .78 to .81; alpha for the total scale was .89. Conclusion: The KHSMS provides a valid and reliable measure of self-management in Korean patients with HIV. Continued psychometric testing is recommended to provide further evidence of validity with this population.
\end{abstract}

Key words: HIV, Self-management, Self-care, Reliability, Validity

\section{INTRODUCTION}

\section{Background}

Since the human immunodeficiency virus (HIV) epidemic began, the prevalence of people infected with HIV has steadily increased. Centers for Disease Control and Prevention estimated that 1,148,200 persons aged 13 older were living with HIV infection in the United States in 2009[1]. In Korea, the total cumulative number of HIV patients was 8,544 in 2011[2]. Among them, 7,860(92\%) were men and 684(8\%) were women. The new incidence rate has increased consistently, with 888 patients newly diagnosed in 2011[2]. At the same time, advances in the anti-retroviral therapy of HIV have lowered the mortality rate

\footnotetext{
*This study was supported by the Korea Centers for Disease Control and Prevention (KCDC) and Hallym University (7-2012-0333).

Address reprint requests to: Park, Yunhee

Department of Nursing, Youngdong University, 310 Taehak-ro, Yeongdong-eup, Yeongdong 370-701, Korea

Tel: +82-43-740-1386 Fax: +82-43-740-1389 E-mail: yhpark118@gmail.com

Received: October 29, 2014 Revised: November 12, 2014 Accepted: March 4, 2015

This is an Open Access article distributed under the terms of the Creative Commons Attribution NoDerivs License. (http://creativecommons. org/licenses/by-nd/4.0) If the original work is properly cited and retained without any modification or reproduction, it can be used and re-distributed in any format and medium.
} 
and extended life expectancy for people living with HIV infection. Of the 8,544 patients in Korea who had been diagnosed with HIV by 2011, the number of survivors was 7,032[2]. Given this, most of those patients infected with HIV need continuous care and management.

In early decades of the HIV epidemic, treatment and care of HIV was considered to require management by an HIV specialist, with the focus on infectious disease control[3]. In the decades since dissemination of anti-retroviral therapy, many scientists have asserted that a paradigm change is needed, from viewing HIV as an acute infectious disease to a chronic disease in need of long-term management[4]. Thus, more and more health care providers are going to be required, to provide continuing health services for the growing numbers of HIV patients. Beginning in 2006, the Korean Centers for Disease Control and Prevention (KCDC) has provided hospital-based counseling services for HIV patients, to enhance their disease adaptation, promote treatment adherence and prevent HIV transmission. Forty percent of HIV survivors $(2,627)$ had received the service as of March 2011.

The World Health Organization[5] defined chronic disease as a condition "requiring ongoing management over a period of years or decades" and included a wide range of health problems, not merely heart disease, diabetes, and asthma, but also HIV, depression, schizophrenia, and musculoskeletal disorders. Siegel and Lekas[6] argued that HIV has several characteristics of a chronic disease: uncertain progression, prescribed treatment regimen, requirement for self-care, changes in social roles and relationships, identity change, and emotional distress. Considering HIV as a chronic disease places a greater importance on the patient's role in treatment compliance and active participation in the care process.

Self-care and self-management are important concepts in effective chronic disease management that emphasize patients' active participation. Lorig and Holman[7] offered a conceptual definition of self-management for persons with chronic disease as bearing responsibility for day-to-day care through the length of the illness and performing lifetime tasks such as taking medication, eating healthily, changing or creating new behaviors or roles, and managing emotional distress. Regarding self-management promotion interventions for HIV patients, physical health, psychological functioning, and social relationships have all been included as common elements[8]. Selfmanagement behaviors have been considered as primary in the care of chronic disease and prevention of comorbidities. HIV has been deemed as a chronic disease in Korea as well, nevertheless, research attempts regarding self-management in HIV patients has been limited by the lack of appropriate measurement instruments.

Health care providers should encourage HIV patients to be aware of the importance of self-management and should provide effective interventions to promote self-management behaviors. To evaluate these interventions and measure self-management in HIV patients, a valid and reliable instrument is needed. The HIV Self-Management Scale was developed by Webel and colleagues to assess self-management in American women living with HIV/ AIDS[4]. However, the applicability of this scale to Korean HIV patients or men has not yet been examined.

\section{Purpose}

The aim of this study was to investigate the validity and reliability of the Korean version of Webel and colleagues' HIV SelfManagement Scale, and to compare the factor structure of the Korean version with the original version.

\section{METHODS}

\section{Study design}

This is the methodological study used a cross-sectional correlational design guided by classical test theory to conduct psychometric analysis.

\section{Setting and sample}

A convenience sample of participants was recruited from the outpatient departments at general hospitals. The eligibility criteria for participating in this study were as follows: patients had to have been diagnosed with HIV, be aged 19 years or older, and be able to respond to the questionnaire. Two hundred fifty questionnaires were distributed in seven general hospitals; 219 com- 
pleted questionnaires were received (response rate of $87.6 \%$ ). Fourteen questionnaires were discarded due to missing data on the major variables, and two questionnaires were excluded because those respondents did not meet eligibility criteria (were only 18 years old). Thus, the final patient sample included 203 participants. The sampling of this study exceeded the recommended criterion of 5 10 participants per item of an instrument for determining the factor structure[9]. Additionally, according to our final model post power analysis, power showed almost 1.0[10]. Thus, the number of individuals in the sample was enough to achieve the purpose of this study.

\section{Ethical consideration}

The ethical committee of the institutional review board (IRB) at Y College of Nursing and Hospital approved all of the study procedures (Nr. IRB 2012-0014). Participants were offered an opportunity to ask any questions and were told that they could end their participation at any time. Participants were asked to sign an informed consent document and complete a pen and paper survey containing the HIV Self-Management Scale and items measuring related variables.

\section{Measurements}

\section{1) HIV self-management}

The HIV Self-Management Scale was developed and revised by Webel et al. [4]. This scale contains 20 items in three domains: daily self-management health practices (12 items), social support of HIV self-management (3 items), and chronic nature of HIV self-management (5 items). Items are rated on 4-point scale: $0=$ not applicable, $1=$ none of the time, $2=$ some of the time, and 3=all of the time. The HIV Self-Management Scale is a self-report questionnaire reflecting the day-to-day decisions that individuals make to manage their disease. Total scores are calculated by adding the scores across all items, with higher scores indicating a higher level of self-management, and possible scores ranged from 0 to 60 . Webel et al. [4] reported the internal consistency of subscales from .72 to .86. Permission was obtained for use in this study from Allison R. Webel (e-mail communication August 25, 2012).

\section{2) Perceived smart patient}

To examine concurrent validity, the concept of "smart patient" was selected as a similar construct to self-management. The variable, self-perception as a smart patient, was measured with a single item created to assess smart patient in this study. After showing the respondent the definition of a smart patient (a person who understands clearly his/her disease condition, communicates openly with health care professionals, and improves their self-management ability by participating in their whole treatment process), the respondent was asked "How smart you are as a HIV patient? "[11]. Their response were recorded on a horizontal visual analogue scale from $0=$ very low to $10=$ very high.

Demographic and clinical characteristics included age, gender, education, job status, type of household, duration diagnosed with HIV, whether they had participated in a self-help group, and whether they knew their own recent viral load.

\section{Translation and content validity procedure}

To create the Korean version of the HIV Self-Management Scale (KHSMS), first the scale was translated from English to Korean by three Korean nursing researchers with expertise in English clinical and health terminology. Second, the Korean version was back-translated into English by a bilingual nursing professional. Then, this English version was reviewed together with the original English by the first researchers who translated the scale and the nursing professional who back-translated. They discussed inconsistences and item meanings in the Korean cultural context. The back-translated and original forms of the scale were compared, and translators suggested minor revisions in several areas to achieve conceptual, semantic and content equivalence between the English and Korean versions. The research committee for this study, including two nursing professionals and a physician who specialized in infectious diseases, confirmed that the Korean version scale was appropriate to measure self-management of HIV patients. Finally, another expert who majored in Korean linguistics from undergraduate to a doctoral degree reviewed the Korean version scale to evaluate the suitability of the Korean expressions. A pilot study was conducted with 10 patients from the out-patient department in a public hospital, to ensure appropriateness and comprehensiveness 
of the questionnaire. Generally, patients in the public hospital had less education compared to patients in the private hospital, but they did not report any inherent difficulty in understanding and answering the items.

Content validity of the KHSMS was determined by an expert panel of nine experienced nurses rating the relevance of each item to the construct self-management. The mean duration of the nurses' experience in caring for HIV patients was 2.18 years. For each item, the appropriateness to measure self-management of HIV patients was rated on a 4-point scale as $1=$ not relevant, $2=$ somewhat relevant, $3=$ quite relevant, and $4=$ highly relevant. The experts were then asked about the clarity and ease of understanding of each item. Although the measure was developed with a sample of women, the items' face validity suggests that they would be appropriate for use with men and women. The expert panel was not directed to evaluate items for use only with women, and none of the expert panel identified any item as problematic for use with men. Thus, the items of the scale were considered to be suitable to use for both men and women. The content validity index for each item (I-CVI) was computed according to Davis[12]. For each item, ratings of 1 and 2 were recoded as 'content invalid', while ratings of 3 and 4 were recoded as 'content valid' (thus dichotomizing the ordinal scale into relevant and not relevant). Then, the I-CVI was calculated as the number of experts giving a rating of valid divided by the total number of experts. An $\mathrm{I}-\mathrm{CVI} \geq .78$ was considered as acceptable, using the criteria of Lynn[13].

\section{Data collection}

The method for data collection was questionnaire survey. Data collection was conducted by the counseling nurse in charge of treatment and care for HIV patients in the outpatient department at each of seven general hospitals. In Korea, sixteen general hospitals provided counseling services supported by KCDC in 2012. Almost half of those hospitals were involved in this study. The researcher met with the counseling nurses during a monthly in-service training, explained the purpose and procedures of the study and requested their participation. All 7 counseling nurses, one nurse in each hospital, participated voluntarily in the study and were trained in the data collection method and process. Be- fore administering the questionnaire to potential participants, the counseling nurse initially screened HIV patients for eligibility criteria for participating in this study, and explained the purpose of the study and stated that participation was voluntary. Participants completed the self-report type questionnaire after signing the consent form. To assess test-retest reliability of the scale, twenty-three participants were asked to complete the same survey 1 to 2 months later. Eleven participants returned the retest survey questionnaire. Each time the participant completed the survey questionnaire, they received individual health counseling in response to their own questions and a $\$ 10$ gift card as compensation for their time. The time needed to complete the survey was 15 to 25 minutes.

\section{Data analyses}

The analyses were carried out using IBM SPSS version 19(SPSS Inc., Chicago, IL, USA) and STATA version 13.0(STATA, College Station, Texas). Demographic data were analyzed using frequencies, means and ranges as appropriate. To examine demographic and clinical differences in self-management, t-test and one-way ANOVA (analysis of variance) were used. Our psychometric validation used a multi-step process including content validation, construct validation, concurrent validation, and reliability assessment.

The content validity was assessed by I-CVI. To evaluate construct validity, exploratory factor analysis and confirmatory factor analysis (CFA) were used. Exploratory factor analysis using principal component analysis (PCA) with Varimax rotation was used for determining factor solution, and CFA was used for testing the factorial structure of the scale. To evaluate the model fit, we examined the relative Chi-Square ( $\left.\chi^{2} / \mathrm{df}\right)$, root mean square error of approximation (RMSEA), comparative fit index (CFI), the standardized root mean square residual (SRMR), and the Tucker-Lewis index (TLI). Kline recommended using $X^{2}$, RMSEA, CFI, SRMR, and TLI[14]. However, we used the $X^{2} / \mathrm{df}$ instead of $X^{2}$ to minimize the impact of small sample size on the model. The $X^{2} / \mathrm{df}$, RMSEA, and SRMR are absolute fit indices and provide the fundamental indication of how well the proposed theory fits the data[15]. The $X^{2} / \mathrm{df}$ is a measure to evaluate overall model fit; a value as low as 2.0 was recommended for a good 
model fit. The RMSEA estimates how well the model fits the covariance matrix[16]. Until the early nineties, an RMSEA in the range of .05 to .10 was considered as a fair fit[10]. However, Steiger suggested that .07 was a stringent upper limit recently[17], and this now seems to be the general consensus[15]. The SRMR is the square root of the difference between the residuals of the sample covariance matrix and the hypothesized covariance model, and values less than .08 are considered as acceptable[15,18]. The CFI and TLI are relative fit indices that compare the $X^{2}$ value to a baseline model[15,19]. A cut-off criterion equal or higher than .90 was recommended for the CFI and TLI[18].

Concurrent validity was assessed using Pearson's correlation between the KHSMS score and self-rating as a smart patient. The internal consistency of the scale was assessed using Cronbach's alpha and test-retest reliability was examined using Pearson's correlation coefficient. In all analyses, a $p$-value of $<.05$ was considered the criterion of statistical significance.

\section{RESULTS}

The participants' ages ranged from 19 to 66 years with a mean (SD) of 41.98(10.84) years. Most were men (92.6\%). Of these participants, $86.2 \%$ had a high school or college education;
73.7\% were not married. The mean length of time since diagnoses of HIV was 7.19(5.45) years. Self-management varied significantly according to knowledge of own recent viral load $(\mathrm{t}=-3.24, p=.001)$ (Table 1$)$.

\section{Content validity}

The range of I-CVI by the expert panel of nine experienced nurses was between .89 and 1.00 except for items 3, 7, 10, and 17, which received .78; thus all of the items were valid measures of the construct.

\section{Construct validity}

For initial exploratory factor analysis, Kaiser's criterion of an eigenvalue $>1.0$ and the scree plot test were used to decide the potential number of factors. By Kaiser's criterion, 4-factor solution was preferred and explained $54.7 \%$ of variance. By the scree plot test, the elbow of the curve was estimated from a 2 to 5-factor solution. Following exploratory factor analysis with 2, 3, 4, and 5-factor designations, and 3-factor solution showed clearest conceptual meaning. Thus, the 3 -factor type was selected as the final solution.

Varimax rotation produced factors of the scale that were sim-

Table 1. Demographic and Medical Characteristics of the Participants

$(N=203)$

\begin{tabular}{|c|c|c|c|c|}
\hline \multirow{2}{*}{ Characteristics } & \multirow{2}{*}{ Categories } & \multirow{2}{*}{$n *(\%)$} & \multicolumn{2}{|c|}{ Self-management } \\
\hline & & & $M \pm S D$ & $p$ \\
\hline Age (yr) & $\begin{array}{l}\leq 30 \\
31 \sim 49 \\
\geq 50\end{array}$ & $\begin{array}{r}28(13.8) \\
126(62.1) \\
49(24.1)\end{array}$ & $\begin{array}{l}39.29 \pm 11.14 \\
39.63 \pm 9.12 \\
41.57 \pm 10.94\end{array}$ & .459 \\
\hline Gender & $\begin{array}{l}\text { Male } \\
\text { Female }\end{array}$ & $\begin{array}{c}187(92.6) \\
15(7.4)\end{array}$ & $\begin{array}{l}39.78 \pm 10.05 \\
43.93 \pm 6.31\end{array}$ & .117 \\
\hline Education level & $\begin{array}{l}\leq \text { Middle school } \\
\text { High school } \\
\geq \text { College }\end{array}$ & $\begin{array}{l}28(13.8) \\
81(39.9) \\
94(46.3)\end{array}$ & $\begin{array}{l}38.21 \pm 12.24 \\
40.78 \pm 8.20 \\
39.97 \pm 10.41\end{array}$ & .494 \\
\hline Job status & $\begin{array}{l}\text { Work for pay } \\
\text { Do not work for pay }\end{array}$ & $\begin{array}{r}129(63.9) \\
73(36.1)\end{array}$ & $\begin{array}{l}40.40 \pm 9.90 \\
39.53 \pm 9.85\end{array}$ & .549 \\
\hline Type of household & $\begin{array}{l}\text { Alone } \\
\text { With family } \\
\text { With friend (s) }\end{array}$ & $\begin{array}{l}77(39.7) \\
92(47.4) \\
25(12.9)\end{array}$ & $\begin{array}{l}40.57 \pm 10.96 \\
39.91 \pm 9.08 \\
40.96 \pm 9.64\end{array}$ & .858 \\
\hline Participation on self-help group & $\begin{array}{l}\text { Participate } \\
\text { Do not participate }\end{array}$ & $\begin{array}{r}25(12.3) \\
178(87.7)\end{array}$ & $\begin{array}{l}42.88 \pm 9.72 \\
39.65 \pm 9.84\end{array}$ & .126 \\
\hline Knowledge of own recent viral load & $\begin{array}{l}\text { Know } \\
\text { Do not know }\end{array}$ & $\begin{array}{r}129(64.2) \\
72(35.8)\end{array}$ & $\begin{array}{l}41.62 \pm 9.03 \\
37.06 \pm 10.51\end{array}$ & .001 \\
\hline
\end{tabular}

*Total of each variable varies because of the exclusion of nonresponse or missing data. 
Table 2. Baseline Distributions and Item Factor Loading of HIV Self-Management Scale

\begin{tabular}{|c|c|c|c|c|c|c|c|c|}
\hline \multirow{3}{*}{ Items } & \multicolumn{2}{|c|}{ Baseline } & \multicolumn{6}{|c|}{ Factor loading } \\
\hline & \multirow{2}{*}{$\begin{array}{c}\text { Original } \\
\text { version }\end{array}$} & \multirow{2}{*}{$\begin{array}{l}\text { Korean } \\
\text { version } \\
M \pm S D\end{array}$} & \multicolumn{3}{|c|}{$\begin{array}{c}\text { Original version } \\
\text { (Webel et al., 2012) }\end{array}$} & \multicolumn{3}{|c|}{ Three factor } \\
\hline & & & 1 & 2 & 3 & 1 & 2 & 3 \\
\hline 1. Staying physically active is an important strategy to manage HIV & $2.31 \pm 0.76$ & $2.53 \pm 0.68$ & .65 & & & .62 & .01 & .07 \\
\hline 2. I succeeded in staying physically active & $2.20 \pm 0.79$ & $2.04 \pm 0.83$ & .59 & & & .68 & .13 & .20 \\
\hline 3. Spirituality/religion is a motivator to manage HIV & $2.36 \pm 0.84$ & $1.45 \pm 1.20$ & .49 & & & .51 & .18 & -.15 \\
\hline 4. I changed some health aspect to manage HIV & $2.41 \pm 0.72$ & $2.24 \pm 0.71$ & .40 & & & .58 & .21 & .28 \\
\hline 5. I succeeded in achieving health goals & $2.21 \pm 0.76$ & $1.84 \pm 0.78$ & 63 & & & .69 & .17 & .26 \\
\hline 6. I modified my diet to manage HIV & $2.17 \pm 0.75$ & $1.78 \pm 0.89$ & .63 & & & .60 & .13 & .10 \\
\hline 7. I had enough time to care health needs, even with family responsibilities & $2.42 \pm 0.78$ & $1.99 \pm 0.76$ & .53 & & & .57 & .16 & .35 \\
\hline 8. I enjoyed often personal time & $2.30 \pm 0.77$ & $1.88 \pm 0.87$ & 67 & & & .41 & .45 & .22 \\
\hline 9. Job responsibilities are helpful to care health & $1.70 \pm 1.22$ & $1.79 \pm 0.96$ & .58 & & & .50 & .34 & .14 \\
\hline 10. Educating others is helpful to control HIV & $1.90 \pm 1.14$ & $1.72 \pm 0.99$ & .41 & & & .19 & .54 & .10 \\
\hline 11. I used positive strategies to relieve stress & $2.12 \pm 0.84$ & $1.89 \pm 0.92$ & .59 & & & .42 & .50 & .30 \\
\hline 12. I can control HIV symptoms and medication side effects & $2.14 \pm 0.86$ & $1.83 \pm 0.86$ & .41 & & & .32 & .51 & .33 \\
\hline 13. I see my counselor or support group if need be & $2.13 \pm 0.90$ & $2.01 \pm 0.92$ & & .73 & & .08 & .75 & .26 \\
\hline 14. Support groups is an important strategy to manage HIV & $1.95 \pm 1.00$ & $1.75 \pm 1.02$ & & .93 & & .10 & .77 & .10 \\
\hline 15. I attended support groups because it motivated to take better care & $1.90 \pm 1.10$ & $1.23 \pm 1.10$ & & .82 & & .11 & .70 & .09 \\
\hline 16. HIV is manageable chronic condition & $2.62 \pm 0.65$ & $2.39 \pm 0.74$ & & & .42 & .15 & .11 & .67 \\
\hline 17. Managing HIV is my top priority task & $2.55 \pm 0.68$ & $2.47 \pm 0.69$ & & & .63 & .38 & .20 & .54 \\
\hline 18. HIV is a motivator to take better care & $2.59 \pm 0.61$ & $2.23 \pm 0.87$ & & & .51 & .47 & .15 & .51 \\
\hline 19. I appoint to see my HIV doctor if need be & $2.60 \pm 0.73$ & $2.44 \pm 0.76$ & & & .49 & .09 & .29 & .75 \\
\hline 20. I have a good relationship with HIV doctor & $2.77 \pm 0.60$ & $2.55 \pm 0.61$ & & & .63 & .06 & .17 & .78 \\
\hline Eigen value & & & & & & 6.81 & 1.59 & 1.35 \\
\hline Percent of variance & & & & & & 34.06 & 7.95 & 6.75 \\
\hline Cumulative percent & & & & & & 34.06 & 42.01 & 48.76 \\
\hline
\end{tabular}

HIV=Human immunodeficiency virus.

Table 3. Summary of Model Fit Indices from Confirmatory Factor Analysis

\begin{tabular}{|c|c|c|c|c|c|c|c|}
\hline \multirow{3}{*}{ Three-factor model } & \multicolumn{7}{|c|}{ Fit indexes } \\
\hline & \multirow{2}{*}{$\chi^{2}$} & \multirow{2}{*}{$d f$} & \multirow{2}{*}{$\chi^{2} / d f$} & \multicolumn{4}{|c|}{ Comparative fit index } \\
\hline & & & & $\mathrm{CFI}$ & TLI & SRMR & RMSEA \\
\hline $\begin{array}{l}\text { Original model } \\
\text { (Webel et al., 2012) }\end{array}$ & 273.36 & 163 & 1.68 & 0.93 & 0.91 & - & 0.05 \\
\hline Original model & 360.74 & 167 & 2.16 & 0.86 & 0.84 & 0.06 & 0.08 \\
\hline Proposed model & 356.69 & 167 & 2.14 & 0.86 & 0.84 & 0.06 & 0.08 \\
\hline Modified model & 272.25 & 164 & 1.66 & 0.92 & 0.91 & 0.05 & 0.06 \\
\hline
\end{tabular}

ple and meaningful conceptually. The three-factor PCA with Varimax rotation showed that the factor loading for scale items was acceptable at above .45(Table 2). The Kaiser-Meyer-Olkin measure was .88, indicating sampling adequacy, and Bartlett's test of sphericity was statistically significant $\left(\chi^{2}=1470.88\right.$, $\mathrm{df}=190, p<.001)$. The final 3 -factor solution explained $48.8 \%$ of the variance.

The factor structure of the HIV self-management scale was assessed with CFA. The initially proposed 3-factor model was not a good model fit: $\chi^{2} / \mathrm{df}$ ratio $=2.14$, $\mathrm{RMSEA}=.08, \mathrm{CFI}=.86$, TLI $=.84$, SRMR $=.06$. Modifying the model by allowing residual correlations between items 1 and 2, between items 13 and 14, and between items 19 and 20 produced a much better fit: $x^{2} / \mathrm{df}$ ratio=1.66, $\mathrm{RMSEA}=.06 \mathrm{CFI}=.92, \mathrm{TLI}=.91, \mathrm{SRMR}=.05$ (Table 3). All factor loadings with the modified model were statistically significant. The three factors in the KHSMS were strongly positively correlated with each other as expected: between Factor 1 and 2, r=.78, between Factor 2 and 3, r=.74, and between Factor 1 and $3, r=.76$ (Figure 1 ). 


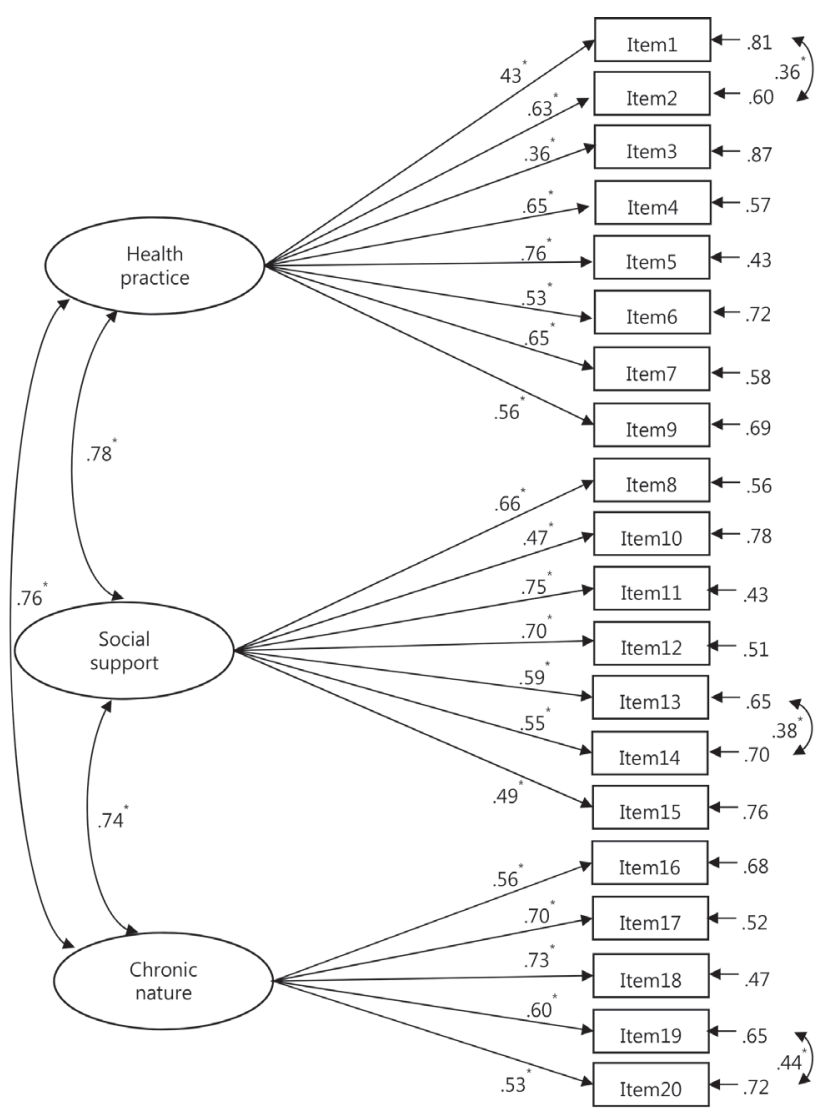

Figure 1. Three factor structure of the Korean version of the HIV Self-Management Scale $\left({ }^{*} p<.001\right)$.

Table 4. Concurrent Validity and Inter-factor Correlation of the Korean Version of HIV Self-management Scale

\begin{tabular}{|c|c|c|c|c|c|}
\hline \multirow{2}{*}{ Factors } & 1 & 2 & 3 & 4 & 5 \\
\hline & \multicolumn{5}{|c|}{$r$} \\
\hline $\begin{array}{l}\text { 1. Perceived level of smart } \\
\text { patient }\end{array}$ & 1.00 & $.41^{*}$ & $.32^{*}$ & $.28^{*}$ & $.50 *$ \\
\hline 2. HIV self-management (total) & & 1.00 & $.86^{\star}$ & $.87^{*}$ & $.78 *$ \\
\hline $\begin{array}{l}\text { 3. Factor } 1 \text { : Daily self- } \\
\text { management health practices }\end{array}$ & & & 1.00 & $.58^{*}$ & $.56^{*}$ \\
\hline $\begin{array}{l}\text { 4. Factor 2: Social support and } \\
\text { HIV self-management }\end{array}$ & & & & 1.00 & $.56^{*}$ \\
\hline $\begin{array}{l}\text { 5. Factor 3: Chronic nature of } \\
\text { HIV self-management }\end{array}$ & & & & & 1.00 \\
\hline
\end{tabular}

\section{Concurrent validity}

Pearson's correlation was used between HIV self-management and perceived smart patient to evaluate concurrent validity. All three factors of HIV self-management were significantly positively correlated with perceived smart patient: between Factor 1 and perceived smart patient, $r=.32$, between Factor 2 and smartness, $r=.28$, and between Factor 3 and smartness, $r=.50$ and total level of HIV self-management was correlated with perceived smart patient $(r=.41)$ as well $(p<.001)$ (Table 4).

\section{Reliability and measurement error}

Internal consistency was measured with Cronbach's alpha coefficient. Cronbach's alpha coefficients for the three factors extracted were satisfactory: Factor 1=.78; Factor 2=.81; and Factor $3=.78$. For the overall items of the HIV Self-Management Scale, Cronbach's alpha coefficient was .89.

Test-retest reliability was examined to assess the scale's stability over time. Retest was carried out 1 to 2 months after the first test $(n=11)$. Pearson's correlation between test and retest revealed good agreement with the $r$ value of .68( $p<.05)$.

\section{DISCUSSION}

The present study showed the first report of the psychometric properties of the KHSMS for Korean patients. The findings are discussed comparing the KHSMS with original version of Webel et al. [4].

Mean level of total self-management was 2.00(0.49), lower than Webel et al. [4] found: 2.64(0.43). A primary difference among participants' characteristics between the present study and prior study was gender proportion. Webel et al. recruited only women, whereas most participants in the present study were men. Reports of the association between gender and selfmanagement among chronic disease patients have been inconsistent. Han et al. [20] reported that Korean American women were more likely than men to have controlled blood pressure and to take a medication. However, Shrestha, Kosalram, and Gopichandran showed that Nepalese men were less likely to have bad dietary practices than Nepalese women[21]. In this study, the lowest scores $(\mathrm{M} \pm \mathrm{SD})$ among the $20 \mathrm{HIV}$ self-management items were found in the responses to two items: "I attended support groups because it motivated me to take better care" (1.23 \pm 1.10) and "Spirituality/religion is a motivator to manage HIV" (1.45 \pm 1.20$)$. These two items also showed the largest difference in mean scores comparing with the Webel et al. study: $1.90 \pm$ 1.10 and $2.36 \pm 0.84$, respectively. One explanation regarding the 
lower mean score in the support group's item is the low rate of current participation in self-help groups in this study sample. Only twelve percent of participants reported participating in a self-help group. Furthermore, in Korea, self-help groups for HIV patients are less common than in American society. Thus, most participants did not have an opportunity to attend support groups. Kara also reported that thirst distress score in Turkish patients on hemodialysis were higher than mean score obtained from American patients as the example of the different scores according to different societies[22]. On the other hand, a possible explanation regarding the lower mean score in the spirituality/ religion item is that the majority of participants in this study were men. Chou's[23] secondary analysis of data from American patients found that HIV-positive women are more likely to use spiritual care activities for their self-care than HIV-positive men. Based on these results, the authors suggest that strategies of HIV self-management might depend on the cultural and social context, and on gender.

In our comparative analysis, participants who knew their own recent viral load had higher scores for self-management than who did not. This result indicated that health care providers should tell patients the precise result of viral load and encourage viral load monitoring to improve their self-management competency. Although we found no studies that examined the relationships between knowledge of viral load and self-management in patients with HIV, studies have showed the positive effects of self-monitoring on health behavior and health outcomes in diabetes or hypertension[24,25].

Notwithstanding that Kaiser's criterion would have indicated a four-factor solution from the initial exploratory factor analysis, a three-factor solution was determined. Authors deliberated on fitness of items composing each factor. Our initial four-factor solution divided the items of daily health practice into two factors. We considered that health practice behaviors are hard to think of separately; for example, physical activity and diet are both related to daily health practice. Comparing with the original version, the three-factor solution showed displacement of 4 items from daily health practice in the original version to social support in the present Korean version. For example item 10 "Educating others is helpful to control HIV" could be connected to the context of social support. Pai et al. [26] also reported that they selected a 4-factor solution by considering of conceptual meaning of the items regarding sexual health knowledge, even though Kaiser's criterion showed a 10-factor solution was preferred at the initial factor analysis. Thus, the researcher should consider conceptual meaning of the group of items making up a factor, and not merely statistical criteria, to decide the number of factors.

The KHSMS's factor structure in the present study suggested several strengths. First, ranges of items' factor loading to Factor 1 were higher compared to the original version. Item loading to daily health practice ranged from .36 to .76 , while the original version showed item loading from .23 to .41[4] (Figure 1). Second, the levels of correlation among the three factors were higher than those of the original version. Pearson correlation coefficients ranged from .74 to .78 , whereas the original version ranged from .24 to .56[4]. Third, subscale Cronbach's alpha coefficients ranged from .78 to .81 ; these were similar with the original version, which ranged from .72 to .86 . Finally, the three-factor model of KHSMS demonstrated a good model fit. This was shown in all model fit indices including $X^{2} / \mathrm{df}$, CFI, TLI, SRMR, and RMSEA (Table 3). This result was congruent with the original study, where the scale demonstrated a CFI of .93 and a RMSEA of .05[4]. The results of the present study suggested that the obtained factor structure of the KHSMS provides good evidence with regard to internal consistency, factorial validity, and model fitness.

Better model fit of the modified model was obtained through allowing correlations of three pairs of items: between items 1 and 2: "Staying physically active is an important strategy to manage HIV" and "I succeeded in staying physically active", between items 13 and 14 and between items 19 and 20. The authors considered that the first two pairs of items were closely related. For example, both items 1 and 2 were related to physical activity, and if a person believed that physical activity was important, they were more likely to succeed in being active. This finding suggests that further study is needed to consider item changes to improve the measurement of HIV self-management. As one possible approach, cognitive interviewing, an interview technique to derive the participant's thoughts, feelings, and interpretations while answering the survey questions, could be used[27]. Gomes et al. [28] reported improvement in measurement of grief by reflecting on participants' feelings and opinions through cognitive 
interviews. This qualitative approach might be helpful to assess the e existence of unclear and/or repetitive items. Using these data, we can consider revision of KHSMS.

The concept of smart patient was selected to evaluate concurrent validity. The concurrent validity of KHSMS was confirmed by strong correlation with self-rated smart patient. A few studies have defined attributes of a smart patient[11,29]. However, those studies have not measured the level of smart patient. Many researchers and clinicians have validly used a single item to measure various concepts such as quality of life, medication adherence, and stress, because a single item can be brief and accurate. Yohannes et al. [30] reported the evidence that the singleitem quality of life measure showed high correlation with a 52item cystic fibrosis quality of life questionnaire for adult patients with cystic fibrosis. The results of the present study showed the first evidence of the validity of this smart patient measure.

A limitation of the study was the use of a single construct to assess concurrent validity. Stronger validity evidence gained through measures of multiple constructs is recommended for future studies. However, the results of the present study showed strong evidence of the validity and reliability of the KHSMS.

\section{CONCLUSIONS}

Psychometric analyses of the KHSMS indicate high reliability and appropriate content, construct and concurrent validity. According to these findings, the authors suggest that the KHSMS is a valid and reliable measure of self-management in Korean patients with HIV. Clinical and public health nurses and researchers can utilize this scale for evaluating patients' capacity for selfmanagement. Nurses and physicians should evaluate the level of self-management of patients to determine their baseline condition. Particular attention should be paid to such evaluations for the patients who did not know their own recent viral load. However, this study also demonstrated that the factorial structure of the KHSMS was somewhat different compared with the original version used with American women. Thus, the authors suggest that further study is needed that includes qualitative approaches to evaluate the need for item development or elimination.

\section{REFERENCES}

1. Korea Federation for HIV/AIDS Prevention. HIV/AIDS statistics [Internet]. Seoul: Author; 2013 [cited 2013 June 16]. Available from: http://www. kaids. or. $\mathrm{kr} /$ ? c $=2 / 37 / 41 / 70$.

2. Centers for Disease Control and Prevention. Monitoring selected national HIV prevention and care objectives by using HIV surveillance data-United States and 6 U. S. dependent areas-2010. HIV Surveillance Supplemental Report. 2011;17(3) [Internet]. Atlanta, GA: Author; 2011 [cited 2013 June 16]. Available from: http:// www. cdc. gov/hiv/library/reports/surveillance/2010/surveillance_ Report_vol_17_no_3.html.

3. Aberg JA. The changing face of HIV care: Common things really are common. Annals of Internal Medicine. 2006;145(6):463-465.

4. Webel AR, Asher A, Cuca Y, Okonsky JG, Kaihura A, Dawson Rose C, et al. Measuring HIV self-management in women living with HIV/AIDS: A psychometric evaluation study of the HIV Selfmanagement Scale. Journal of Acquired Immune Deficiency Syndromes. 2012;60(3):e72-e81. http://dx. doi. org/10. 1097/QAI. 0b013e318256623d

5. World Health Organization. Noncommunicable diseases and mental health cluster. Innovative care for chronic conditions: Building blocks for actions : Global report. Geneva, CH: Autor; 2002.

6. Siegel K, Lekas HM. AIDS as a chronic illness: Psychosocial implications. AIDS. 2002;16(Suppl 4):S69-S76.

7. Lorig KR, Holman H. Self-management education: History, definition, outcomes, and mechanisms. Annals of Behavioral Medicine. 2003;26 (1):1-7.

8. Swendeman D, Ingram BL, Rotheram-Borus MJ. Common elements in self-management of HIV and other chronic illnesses: An integrative framework. AIDS Care. 2009;21(10):1321-1334. http://dx. doi. org/10. 1080/09540120902803158

9. Tinsley HE, Tinsley DJ. Uses of factor analysis in counseling psychology research. Journal of Counseling Psychology. 1987;34(4): 414-424.

10. MacCallum RC, Browne MW, Sugawara HM. Power analysis and determination of sample size for covariance structure modeling. Psychological Methods. 1996;1(2):130-149. http://dx. doi. org/10. 1037//1082-989X. 1. 2. 130

11. Park CS, Yoo YS, Choi DW, Park HJ, Kim JI. Development and evaluation of "hospice smart patient" service program. Journal of Korean Academy of Nursing. 2011;41(1):9-17. http://dx. doi. org/10. 4040/jkan. 2011. 41. 1.9

12. Davis LL. Instrument review: Getting the most from a panel of experts. Applied Nursing Research. 1992;5(4):194-197. http://dx. doi. org/10. 1016/S0897-1897(05)80008-4

13. Lynn MR. Determination and quantification of content validity. Nursing Research. 1986;35(6):382-385.

14. Kline RB. Principles and practice of structural equation modeling. 3rd ed. New York, NY: Guilford Press; 2010. 
15. Hooper D, Coughlan J, Mullen MR. Structural equation modelling: Guidelines for determining model fit. Electronic Journal of Business Research Methods. 2008;6(1):53-60.

16. Byrne BM. Structural equation modeling with LISREL, PRELIS, and SIMPLIS: Basic concepts, applications, and programming. Mahwah, NJ: Lawrence Erlbaum Associates; 2014.

17. Steiger JH. Understanding the limitations of global fit assessment in structural equation modeling. Personality and Individual Differences. 2007;42(5):893-898.

http://dx. doi. org/10. 1016/j. paid. 2006. 09. 017

18. Hu L, Bentler PM. Cutoff criteria for fit indexes in covariance structure analysis: Conventional criteria versus new alternatives. Structural Equation Modeling: A Multidisciplinary Journal. 1999;6(1):1-55. http://dx. doi. org/10. 1080/10705519909540118

19. McDonald RP, Ho MH. Principles and practice in reporting structural equation analyses. Psychological Methods. 2002;7(1): 64-82.

20. Han HR, Kim KB, Kang J, Jeong S, Kim EY, Kim MT. Knowledge, beliefs, and behaviors about hypertension control among middle-aged Korean Americans with hypertension. Journal of Community Health. 2007;32(5):324-342. http://dx. doi. org/10. 1007/s10900-007-9051-y

21. Shrestha AD, Kosalram K, Gopichandran V. Gender difference in care of type 2 diabetes. JNMA: Journal of the Nepal Medical Association. 2013;52(189) :245-250.

22. Kara B. Validity and reliability of the Turkish version of the thirst distress scale in patients on hemodialysis. Asian Nursing Research. 2013;7(4):212-218.

http://dx. doi. org/10. 1016/j. anr. 2013. 10. 001

23. Chou FY. Testing a predictive model of the use of HIV/AIDS symptom self-care strategies. AIDS Patient Care and STDS. 2004;18(2):109-117. http://dx. doi. org/10. 1089/108729104322802533
24. Aschner P, Horton E, Leiter LA, Munro N, Skyler JS. Practical steps to improving the management of type 1 diabetes: Recommendations from the global partnership for effective diabetes management. International Journal of Clinical Practice. 2010;64(3): 305-315. http://dx. doi. org/10. 1111/j. 1742-1241. 2009. 02296. x

25. Breaux-Shropshire TL, Brown KC, Pryor ER, Maples EH. Relationship of blood pressure self-monitoring, medication adherence, self-efficacy, stage of change, and blood pressure control among municipal workers with hypertension. Workplace Health \& Safety. 2012;60(7):303-311. http://dx. doi. org/10. 3928/21650799-20120625-04

26. Pai HC, Lee S, Yen WJ, Lee MY. Testing of the factor structure of the sexual health knowledge measure with young adolescent Taiwanese girls. Health Care for Women International. 2013;34(10):878-890. http://dx. doi. org/10. 1080/07399332. 2012. 700357

27. Willis GB. Cognitive interviewing: A tool for improving questionnaire design. Thousand Oaks, CA: Sage; 2005.

28. Gomes B, McCrone P, Hall S, Riley J, Koffman J, Higginson IJ. Cognitive interviewing of bereaved relatives to improve the measurement of health outcomes and care utilisation at the end of life in a mortality followback survey. Supportive Care in Cancer. 2013;21 (10):2835-2844. http://dx. doi. org/10. 1007/s00520-013-1848-x

29. Kim YM, Bazant E, Storey JD. Smart patient, smart community: Improving client participation in family planning consultations through a community education and mass-media program in Indonesia. International Quarterly of Community Health Education. 2006;26 (3):247-270. http://dx. doi. org/10. 2190/IQ. 26. 3. d

30. Yohannes AM, Dodd M, Morris J, Webb K. Reliability and validity of a single item measure of quality of life scale for adult patients with cystic fibrosis. Health and Quality of Life Outcomes. 2011;9:105. http://dx. doi. org/10. 1186/1477-7525-9-105 